\title{
Study of Carbon Nanotube-Supported Platinum Nanocatalyst Fabricated with Sodium Formate Reducing Agent in Ethylene Glycol Suspension
}

\author{
C. W. Mason and A. M. Kannan \\ Fuel Cell Research Laboratory, Engineering Technology Department, Arizona State University, Mesa, AZ 85212, USA
}

Correspondence should be addressed to A. M. Kannan, amk@asu.edu

Received 14 February 2011; Accepted 14 March 2011

Academic Editors: K. S. Coleman, E. Menna, and H. Tang

Copyright (C) 2011 C. W. Mason and A. M. Kannan. This is an open access article distributed under the Creative Commons Attribution License, which permits unrestricted use, distribution, and reproduction in any medium, provided the original work is properly cited.

A simple method to prepare a durable, low platinum-loading catalyst layer for the cathode in a proton exchange membrane fuel cell is tested and described. Multiwalled carbon nanotubes (MWCNTs) are functionalized with citric acid and then suspended in ethylene glycol. Here, platinum nanoparticles $(\sim 4 \mathrm{~nm})$ are loaded onto the surface of the MWCNTs after hexachloroplatinic acid is reduced by aqueous sodium formate. A peak performance of $813 \mathrm{~mW} \cdot \mathrm{cm}^{-2}$ was achieved with a total membrane electrode assembly (MEA) platinum catalyst loading of $0.2 \mathrm{mg} \cdot \mathrm{cm}^{-2}\left(0.1 \mathrm{mg} \cdot \mathrm{cm}^{-2}\right.$ anode $/ 0.1 \mathrm{mg} \cdot \mathrm{cm}^{-2}$ cathode), in $\mathrm{H}_{2} / \mathrm{O}_{2}(\mathrm{ambient}$ pressure), at $80^{\circ} \mathrm{C}$, with a Nafion 212 membrane. Peak power density only decreased by $23 \%$ after 1500 potentials cycles (ranged from 0.1 to $1.2 \mathrm{~V}$, and vice versa, with a $50 \mathrm{mV} / \mathrm{s}$ scan rate, flowing $\mathrm{H}_{2} / \mathrm{N}_{2}$ at $80^{\circ} \mathrm{C}$ ). Transmission electron microscopy (TEM) images show the morphology and distribution of the platinum nanoparticles loaded onto the surface of the MWCNTs.

\section{Introduction}

The use of the noble metal, platinum $(\mathrm{Pt})$, as a catalyst in proton exchange membrane fuel cell (PEMFC) applications has been known to be cost prohibitive. Lowering the amount of platinum used or replacing it entirely with an alternative catalyst material are both valid means by which to overcome this issue. Until a breakthrough is made in finding a durable, high-performance alternative catalyst material, platinum, and alloys with platinum, are still the most effective and prevalent catalyst materials used.

Decreasing the amount of this costly noble metal on the cathode has been a topic of significant interest for many years now, as it is well known that the oxygen reduction reaction (ORR) proceeds at a relatively slow rate [1]. By improving the utilization of platinum, its usage is minimized, and performance is improved. In the catalyst layer, this can be accomplished by better platinum particle distribution, smaller particle size, or an increase in the number of particles that are in the three-phase boundary region [2].
The catalyst layer support onto which platinum nanoparticles are loaded can have a major impact upon particle distribution in particular. Multiwalled carbon nanotubes (MWCNTs) are one such material that can be used to promote better utilization of platinum, compared to traditionally used carbon black materials, such as Vulcan XC72 [3]. MWCNTs possess high electrochemical stability, conductivity, surface area, and mechanical strength [4]. To load the surface of the MWCNTs with Pt nanoparticles, some form of surface modification is almost always required. These usually fall under the category of either covalent or noncovalent modification. Covalent modification involves surface functionalization of the CNTs with reactive functional groups $[5,6]$. Noncovalent modification has also been explored for a variety of applications, as it does not involve changing the surface structure of the CNT. Interactions of this nature between the surface of the $\mathrm{CNT}$ and the functional group, in these cases, can occur through hydrogen bonding, Van der Waals forces, and others [7]. 
TABLE 1: Experimental parameters and fuel cell performance of various samples.

\begin{tabular}{lccccc}
\hline Sample & $\begin{array}{c}\text { Citric acid } \\
(\mathrm{mg})\end{array}$ & $\begin{array}{c}\text { Reduction } \\
\text { temperature } \\
\left({ }^{\circ} \mathrm{C}\right)\end{array}$ & $\begin{array}{c}800^{\circ} \mathrm{C} \\
\text { treatment } \\
\text { in Argon }\end{array}$ & $\begin{array}{c}\text { SDS } \\
(\mathrm{mg})\end{array}$ & $\begin{array}{c}\text { Peak power } \\
\left(\mathrm{mW} \cdot \mathrm{cm}^{-2}\right)\end{array}$ \\
\hline C1 & 200 & 90 & No & - & 378 \\
C2 & 200 & 70 & No & - & 591 \\
C3 & 200 & 90 & Yes & - & 605 \\
C4 & 200 & 70 & Yes & - & 813 \\
C5 & - & 70 & No & 400 & 589 \\
C6 & - & 70 & Yes & 400 & 569 \\
C7 & 200 & 70 & No & 400 & 187 \\
C8 & 200 & 70 & Yes & 400 & 250 \\
C9 & - & 70 & No & 400 & 561 \\
C10 & - & 70 & Yes & 400 & 710 \\
\hline
\end{tabular}

With regard to the commonly used covalent modification method, functional groups on the surface of the CNT, such as hydroxyl $(-\mathrm{OH})$ and carboxyl $(-\mathrm{COOH})$ groups, can be created with a variety of substances, usually strong, acidic oxidizing agents. $\mathrm{HNO}_{3}, \mathrm{H}_{2} \mathrm{SO}_{4}, \mathrm{HCl}$, and $\mathrm{H}_{2} \mathrm{O}_{2}$ have all been used successfully under various conditions to accomplish the functionalization process $[8,9]$. Generally, methods using these chemicals require significant washing and filtering after functionalization of CNTs, while the potential for impurities to exist mixed with CNTs will still remain. Poh et al. described a method by which aqueous citric acid was used to functionalize the CNTs without requiring a subsequent washing and filtering step [10]. Additionally, the process was shown to introduce more surface carboxyl groups to the CNTs than using $\mathrm{HNO}_{3} / \mathrm{H}_{2} \mathrm{SO}_{4}$.

Noncovalent modification is an alternative method through which platinum nanoparticles can be effectively anchored to the surface of the CNTs. Sodium dodecyl sulfate (SDS), also known as sodium lauryl sulfate, and other similar substances can potentially be used in noncovalent modification methods. Most notably, SDS has been used to promote homogeneous dispersion and proper Pt particle size on the surface of CNTs [11]. Additionally, SDS is capable of enabling the homogeneous dispersion of the CNTs, themselves, in a suspension $[12,13]$. This can be very useful in that it can ensure the decoration of Pt nanoparticles on each on every nanotube, not just the outer surfaces of a bundle of nanotubes, which can be a hindrance to other fabrication methods using different materials.

Many methods have been devised to load platinum or platinum-based alloy nanoparticles onto the surface of CNTs. These include, but are not limited to, wet chemical impregnation [14-16], electrodeposition [17-19], colloidal [20-22], and ion exchange $[23,24]$. With the exception of electrodeposition, a variety of reducing agents are used in these processes to reduce the platinum precursor to elemental platinum nanoparticles of a desired size. Commonly used agents include sodium borohydride, formic acid, various alcohols, and flowing hydrogen gas (at elevated temperatures). Aqueous sodium formate ( $\mathrm{HCOONa}$ ) has previously been used in the literature as a more mild, yet effective reducing agent [25]. Previous studies in our lab have also successfully used sodium formate as a reducing agent [26].

In this study, the performance of Pt/MWCNT catalyst created through a wet chemical impregnation method is evaluated. The catalyst is fabricated with citric acid or SDS functionalized MWCNTs, in ethylene glycol suspension, using aqueous sodium formate to reduce the hexachloroplatinic acid $\left(\mathrm{H}_{2} \mathrm{PtCl}_{6}\right)$ platinum precursor to nanoparticles of the ideal, more stable 4-5 $\mathrm{nm}$ size [27]. Often, ethylene glycol is itself used as the reducing agent through heating to it's boiling point. But to date, and to the knowledge of the authors of this paper, this is the first time that the sodium formate reduction process in an ethylene glycol suspension has been investigated as a means to fabricate Pt/MWCNT catalyst.

\section{Experimental}

2.1. Materials. MWCNTs (OD $20-30 \mathrm{~nm},>98 \%$ purity) were obtained from Cheaptubes Co., and Hexachloroplatinic acid $\left(\mathrm{H}_{2} \mathrm{PtCl}_{6} \cdot 6 \mathrm{H}_{2} \mathrm{O}\right)$ was purchased from Sigma-Aldrich, ethylene glycol from VWR, citric acid from EMD, SDS $\left(\mathrm{C}_{12} \mathrm{H}_{25} \mathrm{SO}_{4} \mathrm{Na}\right)$ from Fisher Scientific, and sodium formate ( $\mathrm{HCOONa}$ ) from Spectrum Chemicals.

2.2. Catalyst Preparation. MWCNTs that underwent citric acid functionalization were mixed with $100 \mathrm{~mL}$ of deionized (DI) water and either $200 \mathrm{mg}$ or $1000 \mathrm{mg}$ of anhydrous citric acid. The mixture was then sonicated for 15 minutes, followed by boiling at $350^{\circ} \mathrm{C}$ for half an hour, leaving dried functionalized nanotubes (F-MWCNTs).

To deposit platinum, $32 \mathrm{mg}$ of MWCNTs were sonicated with $20 \mathrm{~mL}$ of ethylene glycol until the CNTs were as well dispersed as possible, which usually took about 5 minutes, with vigorous stirring. In some tests, SDS was added before sonication, either in the amount of 200 or $400 \mathrm{mg}$. The solution was heated to either $60^{\circ} \mathrm{C}$ or $75^{\circ} \mathrm{C}$. The platinum precursor, $\mathrm{H}_{2} \mathrm{PtCl}_{6} \cdot 6 \mathrm{H}_{2} \mathrm{O}$ in ethylene glycol, would then be added to the suspension in the amount of $0.8 \mathrm{~mL}$ at $0.05 \mathrm{M}$. Ideally, this would yield catalyst with $20 \mathrm{wt} \%$ Pt. Then, $0.8 \mathrm{~mL}$ of $1 \mathrm{M}$ aqueous sodium formate would be added, and the suspension would be left to stir at the set temperature for about half an hour to ensure the reduction process proceeds to completion.

Ethylene glycol possesses a big advantage over water when filtering and washing the catalyst after reduction of the Pt precursor. During filtering, using a Buchner funnel, the catalyst materials stay stuck together while still allowing for easy washing with DI water. It greatly simplifies this aspect of the fabrication process. Thus, after the reduction process is complete, the catalyst is filtered and washed with DI water and then dried at $350^{\circ} \mathrm{C}$ for half an hour. At this point, the catalyst would either be tested or further treated in Argon (Ar) atmosphere at $800^{\circ} \mathrm{C}$ in a Thermolyne tubular furnace for 2 hours. Table 1 outlines all of the variables adjusted during the entire catalyst fabrication process, the peak power density during testing, and labels them $\mathrm{C} 1$ through C10.

For comparison, $\mathrm{Pt} / \mathrm{MWCNT}$ catalyst was also prepared using a proven, two-phase transfer process. Its fabrication 
procedure was outlined by Lin et al. [26]. In the two graphs, it is referred to as "Pt/MWCNT_Old".

2.3. Membrane Electrode Assembly Fabrication. The membrane electrode assemblies (MEAs) were coated with $\mathrm{Pt} / \mathrm{C}$ commercial catalyst (TKK, Japan) on the anode side and the fabricated Pt/MWCNT catalyst on the cathode side. Catalyst ink was prepared with isopropanol and $5 \mathrm{wt} \% \mathrm{Du}$ Pont Nafion dispersion (Ion Power Inc., USA). Nafion content was set to $30 \mathrm{wt} \%$ of the overall dried catalyst layer weight to provide ionic conductively and extend the reaction zone. The catalyst ink would be sprayed on a $5 \mathrm{~cm}^{2}$ area of a Du Pont Nafion 212 membrane (Ion Power Inc.), with loadings of $0.1 \mathrm{mg} \cdot \mathrm{cm}^{-2}$ of Pt on both the anode and cathode. The catalyst-coated MEA would then be vacuum dried at $70^{\circ} \mathrm{C}$ for $15 \mathrm{~min}$ before being installed in the fuel cell.

2.4. Evaluation. The MEA is installed into the test cell with $5 \mathrm{~cm}^{2}$ active area (Fuel Cell Technologies Inc., Albuquerque, NM, USA). The GDLs used for testing were fabricated by a process previously described by our lab, with the carbon paper substrates courtesy of Hollingsworth and Vose [28]. Silicone-coated fabric gaskets (Product\# CF1007, Saint-Gobain Performance Plastics, USA) provided sealing, with a torque of $10 \mathrm{~N} \cdot \mathrm{m}$. A Greenlight G50 Test Station (Hydrogenics, Canada) was used to evaluate performance with the cell operating at $80^{\circ} \mathrm{C}, 100 \% \mathrm{RH}$, with $200 \mathrm{cc} / \mathrm{min}$ flowing $\mathrm{H}_{2}$ and $\mathrm{O}_{2}$. High flow rates ensured the cell was never starved for reactants. Durability of the catalysts was examined with potential cycling from $0.1 \mathrm{~V}$ and $1.2 \mathrm{~V}$ and vice versa with a PARSTAT 2273 (AMETEK, USA) at $50 \mathrm{mV} \cdot \mathrm{s}^{-1}$ scan rate and $80^{\circ} \mathrm{C}$, with humidified $\mathrm{H}_{2} / \mathrm{N}_{2}$.

2.5. Characterization. Imaging of the Pt/MWCNT catalyst was performed with a Philips CM200-FEG transmission electron microscope (TEM). This enabled direct examination of Pt particle distribution and size.

\section{Results and Discussion}

For the samples that were fully evaluated, fabrication and performance data is shown in Table 1. $200 \mathrm{mg}$ was found to be an effective amount to use in the functionalization process. Less than that produced inconsistently functionalized nanotubes, with widely varying performance results after platinum deposition. More than that caused significant ohmic overpotentials to be observed during catalyst evaluation in the fuel cell.

The reduction temperature was also another interesting variable that was initially adjusted during this study. The two set temperatures of $70^{\circ} \mathrm{C}$ and $90^{\circ} \mathrm{C}$ were shown to effectively produce $\mathrm{Pt} / \mathrm{MWCNT}$ catalyst. Temperatures much above $90^{\circ} \mathrm{C}$ did not produce desirable or consistent results. Temperatures much below $70^{\circ} \mathrm{C}$ were not effective at promoting the reduction of the $\mathrm{H}_{2} \mathrm{PtCl}_{6}$. Using a temperature of $70^{\circ} \mathrm{C}$, higher-performance samples were consistently produced, which is why this set temperature was used for a majority of the fabrication procedures.

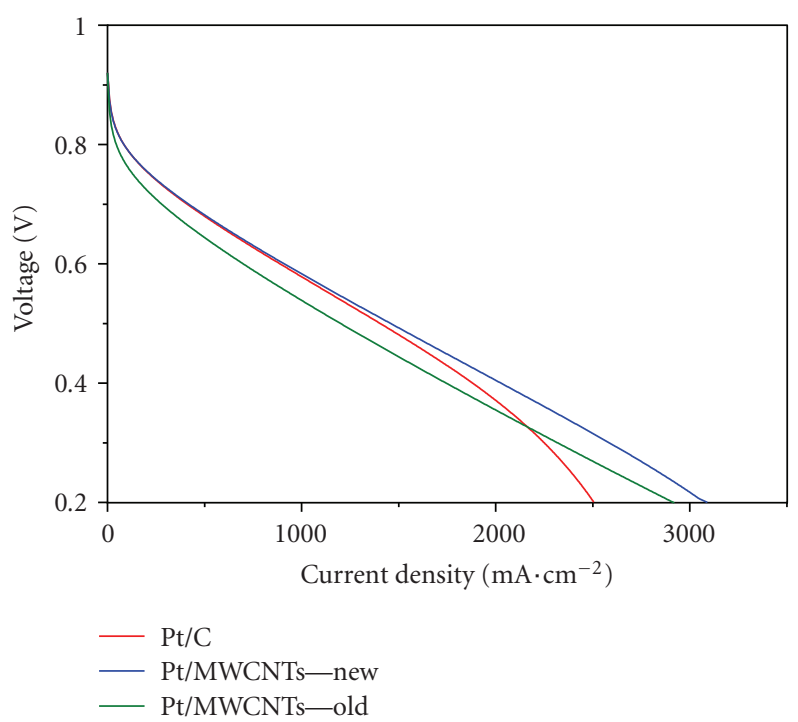

FIgure 1: Polarization data of MEAs fabricated using Pt/MWCNTs synthesized with (old) and without (new) SDS along with that of commercial $\mathrm{Pt} / \mathrm{C}$ using $\mathrm{H}_{2} / \mathrm{O}_{2}$ at $80^{\circ} \mathrm{C}$.

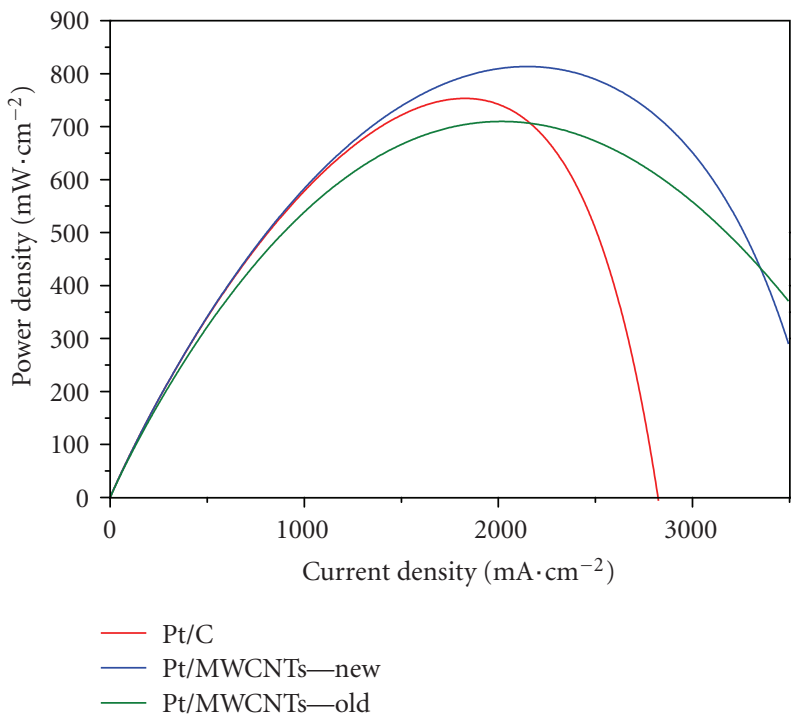

FIgure 2: Power density data of MEAs fabricated using $\mathrm{Pt} / \mathrm{MWCNTs}$ synthesized with (old) and without (new) SDS along with that of commercial Pt/C using $\mathrm{H}_{2} / \mathrm{O}_{2}$ at $80^{\circ} \mathrm{C}$.

Catalysts that were fabricated were tested both before and after treatment at $800^{\circ} \mathrm{C}$ in inert Argon atmosphere. This is done to remove functional groups, which would otherwise cause increased resistance in the catalyst layer. In certain situations, though, the treatment would cause particle agglomeration, which would lend to decreased performance.

Lastly, SDS was used in some of the experiments to improve dispersive properties of the MWCNTs in the ethylene glycol. Additionally, the nonpolar covalent modification ability of SDS provides another option for anchoring platinum nanoparticles to the surface of the MWCNTs. 


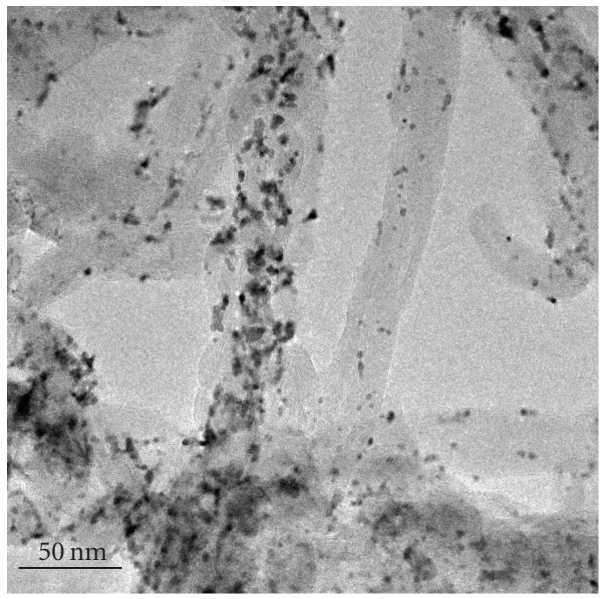

(a)

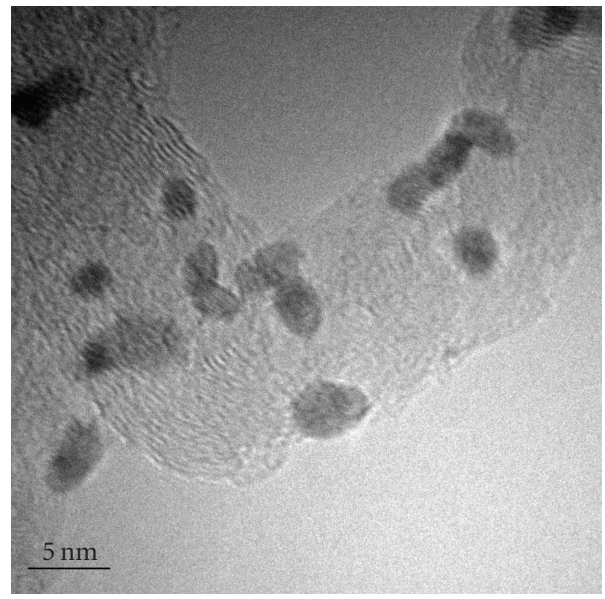

(b)

Figure 3: HRTEM image of Pt/MWCNTs at (a) low magnification and (b) high magnification.

For comparison, SDS was used with both nanotubes that were and were not functionalized with citric acid. A study of SDS in aqueous mediums was published by our research group in which the phenomena associated with nonpolar covalent modification were examined in more detail [29].

As seen in Table 1, ideal performance was observed at a reduction temperature of $70^{\circ} \mathrm{C}$. Heat treatment at $800^{\circ} \mathrm{C}$ consistently improved performance in all samples, except in the case of C5 and C6. Sample C4 achieved the highest performance of all the samples tested in this study. Yet, it is in our opinion that the use of SDS in the catalyst fabrication process has significant room left for optimization and should be able to improve upon the performance of $\mathrm{C} 10$. This is in contrast to the process used with $\mathrm{C} 4$, which is already well optimized.

The performance of the commercial reference catalyst and C4 is compared to one another in Figures 1 and 2. C4 is referred to as "Pt/MWCNTs-New," while the catalyst prepared using an older two-phase transfer method is called "Pt/MWCNTs-Old." Also, note that the electrochemically active surface area for C4 (Pt/MWCNTs-New) was calculated to be $194 \mathrm{~cm}^{2} \cdot \mathrm{mg}^{-1}$, while the commercial catalyst was $141 \mathrm{~cm}^{2} \cdot \mathrm{mg}^{-1}$. As you will see, the increased surface area did not translate into improved performance in the activation polarization region. Figure 1 shows cell voltage with respect to current density, while Figure 2 shows power density with respect to current density. As previously mentioned, the platinum loading is $0.1 \mathrm{mg} \cdot \mathrm{cm}^{-2}$ on both the anode and cathode, for all samples. It is immediately apparent upon inspection of the first graph that the overpotentials in the activation and ohmic regions are almost exactly the same for the commercial sample and the new MWCNT sample. The difference in peak power density is mainly a result of differences in overpotentials in the concentration region. This can likely be attributed to the improved hydrophobic properties of MWCNTs, which are well known. These two samples both underwent durability testing using cyclic voltammetry as previously
TABLE 2: Comparison of PEMFC peak power density durability data.

\begin{tabular}{lccc}
\hline \multirow{2}{*}{ Catalysts } & \multicolumn{2}{c}{ Power density $\left(\mathrm{mW} \cdot \mathrm{cm}^{-2}\right)$} & \\
& Before cycling & After cycling & Loss $(\%)$ \\
\hline Commercial Pt/C & 753 & 587 & 22 \\
Pt/MWCNT (\# C4) & 813 & 623 & 23 \\
\hline
\end{tabular}

described. This accelerates platinum dissolution and particle agglomeration in a controlled, repeatable manner. The power density data before and after cycling is presented in Table 2.

Figures 3(a) and 3(b) show TEM images of sample C4. While particle dispersion could be better, there is limited agglomeration, ensuring high utilization of the platinum present. Figure 3(b) shows the shape and size of the platinum crystal, which is $4-5 \mathrm{~nm}$ in size.

\section{Conclusions}

Pt/MWCNTs catalysts were successfully fabricated using a wetchemical method, with ethylene glycol serving as the medium in which the MWCNTs are suspended in and sodium formate as the reducing agent. Polar and nonpolar covalent MWCNT functionalization methods were both used with success. This shows that they are still advantages in using ethylene glycol in ways other than the wellstudied, higher temperature, polyol methods. There are many avenues available to improve upon this process. Functionalization of the MWCNTs with citric acid has proven to be effective, and there may indeed be room left for optimization. Further in-depth studies quantifying the degree of oxidation that citric acid provides to the MWCNTs may prove useful. Nonetheless, nonpolar covalent modification with compounds, such as SDS, may ultimately prove to be the most effective at creating catalysts with properly dispersed and sized nanoparticles attached to the surface of the MWCNTs. Continued work in this area will 
likely prove to be successful, especially if work is undertaken to take advantage of the micelle-forming capabilities of SDS in water. Additionally, combining some water with the ethylene glycol should improve the cost effectiveness of this method, while still retaining the advantages ethylene glycol has with regard to filtering and washing. The last issue that may need to be addressed, on a more general note, is the Nafion content in the Pt/MWCNT catalyst layer. The optimal weight percentage of Nafion electrolyte for these types of catalysts may indeed be different than from traditional commercial catalysts. An investigation of this with high quality Pt/MWCNT catalyst may yield easily obtainable performance improvements.

\section{Acknowledgments}

Assistance from J. F. Lin and A. Adame with materials preparation and testing is duly acknowledged and greatly appreciated. Thanks to Hollingsworth and Vose for the carbon paper substrates utilized in the GDLs for all testing performed in the lab. Imaging work conducted by Karl Weiss of the LeRoy Eyring Center for Solid State Science at Arizona State University is gratefully acknowledged and appreciated.

\section{References}

[1] X. Yuan and H. Wang, "PEM fuel cell fundamentals," in PEM Fuel Cell Electrocatalysts and Catalyst Layers, J. Zhang, Ed., Springer, New York, NY, USA, 2008.

[2] F. Barbir, PEM Fuel Cells, Academic Press, 2005.

[3] E. Antolini, "Carbon supports for low-temperature fuel cell catalysts," Applied Catalysis B, vol. 88, no. 1-2, pp. 1-24, 2009.

[4] P. M. Ajayan and O. Z. Zhou, "Applications of carbon nanotubes," Topics in Applied Physics, vol. 80, pp. 391-425, 2001.

[5] A. Hirsch, "Functionalization of single-walled carbon nanotubes," Angewandte Chemie-International Edition, vol. 41, no. 11, pp. 1853-1859, 2002.

[6] D. Tasis, N. Tagmatarchis, A. Bianco, and M. Prato, "Chemistry of carbon nanotubes," Chemical Reviews, vol. 106, no. 3, pp. 1105-1136, 2006.

[7] Y. Lin, S. Taylor, H. Li et al., "Advances toward bioapplications of carbon nanotubes," Journal of Materials Chemistry, vol. 14, no. 4, pp. 527-541, 2004.

[8] A. G. Osorio, I. C. L. Silveira, V. L. Bueno, and C. P. Bergmann, " $\mathrm{H}_{2} \mathrm{SO}_{4} / \mathrm{HNO}_{3} / \mathrm{HCl}$-functionalization and its effect on dispersion of carbon nanotubes in aqueous media," Applied Surface Science, vol. 255, no. 5, pp. 2485-2489, 2008.

[9] C. Xu, J. Chen, Y. Cui et al., "Influence of the surface treatment on the deposition of platinum nanoparticles on the carbon nanotubes," Advanced Engineering Materials, vol. 8, no. 1-2, pp. 73-77, 2006.

[10] C. K. Poh, S. H. Lim, H. Pan, J. Lin, and J. Y. Lee, "Citric acid functionalized carbon materials for fuel cell applications," Journal of Power Sources, vol. 176, no. 1, pp. 70-75, 2008.

[11] Y. Wang, X. Xu, Z. Tian, Y. Zong, H. Cheng, and C. Lin, "Selective heterogeneous nucleation and growth of sizecontrolled metal nanoparticles on carbon nanotubes in solution," Chemistry, vol. 12, no. 9, pp. 2542-2549, 2006.

[12] V. C. Moore, M. S. Strano, E. H. Haroz et al., "Individually suspended single-walled carbon nanotubes in various surfactants," Nano Letters, vol. 3, no. 10, pp. 1379-1382, 2003.
[13] K. Moshammer, F. Hennrich, and M. M. Kappes, "Selective suspension in aqueous sodium dodecyl sulfate according to electronic structure type allows simple separation of metallic from semiconducting single-walled carbon nanotubes," Nano Research, vol. 2, no. 8, pp. 599-606, 2009.

[14] N. Rajalakshmi, H. Ryu, M. M. Shaijumon, and S. Ramaprabhu, "Performance of polymer electrolyte membrane fuel cells with carbon nanotubes as oxygen reduction catalyst support material," Journal of Power Sources, vol. 140, no. 2, pp. 250-257, 2005.

[15] T. Matsumoto, T. Komatsu, H. Nakano et al., "Efficient usage of highly dispersed $\mathrm{Pt}$ on carbon nanotubes for electrode catalysts of polymer electrolyte fuel cells," Catalysis Today, vol. 90, no. 3-4, pp. 277-281, 2004.

[16] Y. T. Kim, K. Ohshima, K. Higashimine et al., "Fine size control of platinum on carbon nanotubes: from single atoms to clusters," Angewandte Chemie-International Edition, vol. 45, no. 3, pp. 407-411, 2006.

[17] K. H. Choi, H. S. Kim, and T. H. Lee, "Electrode fabrication for proton exchange membrane fuel cells by pulse electrodeposition," Journal of Power Sources, vol. 75, no. 2, pp. 230-235, 1998.

[18] S. D. Thompson, L. R. Jordan, and M. Forsyth, "Platinum electrodeposition for polymer electrolyte membrane fuel cells," Electrochimica Acta, vol. 46, no. 10-11, pp. 1657-1663, 2001.

[19] K. Saminathan, V. Kamavaram, V. Veedu, and A. M. Kannan, "Preparation and evaluation of electrodeposited platinum nanoparticles on in situ carbon nanotubes grown carbon paper for proton exchange membrane fuel cells," International Journal of Hydrogen Energy, vol. 34, no. 9, pp. 3838-3844, 2009.

[20] C. L. Lee, Y. C. Ju, P. T. Chou, Y. C. Huang, L. C. Kuo, and J. C. Oung, "Preparation of Pt nanoparticles on carbon nanotubes and graphite nanofibers via self-regulated reduction of surfactants and their application as electrochemical catalyst," Electrochemistry Communications, vol. 7, no. 4, pp. 453-458, 2005.

[21] X. Li, S. Ge, C. L. Hui, and I. M. Hsing, "Well-dispersed multiwalled carbon nanotubes supported platinum nanocatalysts for oxygen reduction," Electrochemical and Solid-State Letters, vol. 7, no. 9, pp. A286-A289, 2004.

[22] X. Li and I. M. Hsing, "The effect of the Pt deposition method and the support on Pt dispersion on carbon nanotubes," Electrochimica Acta, vol. 51, no. 25, pp. 5250-5258, 2006.

[23] Y. Shao, G. Yin, J. Wang, Y. Gao, and P. Shi, "Multi-walled carbon nanotubes based Pt electrodes prepared with in situ ion exchange method for oxygen reduction," Journal of Power Sources, vol. 161, no. 1, pp. 47-53, 2006.

[24] J. Wang, G. Yin, Y. Shao, Z. Wang, and Y. Gao, "Platinum deposition on multiwalled carbon nanotubes by ion-exchange method as electrocatalysts for oxygen reduction," Journal of the Electrochemical Society, vol. 154, no. 7, pp. B687-B693, 2007.

[25] L. Xiong, A. M. Kannan, and A. Manthiram, "Pt-M (M $=\mathrm{Fe}, \mathrm{Co}, \mathrm{Ni}$ and $\mathrm{Cu}$ ) electrocatalysts synthesized by an aqueous route for proton exchange membrane fuel cells," Electrochemistry Communications, vol. 4, no. 11, pp. 898-903, 2002.

[26] J. F. Lin, V. Kamavaram, and A. M. Kannan, "Synthesis and characterization of carbon nanotubes supported platinum nanocatalyst for proton exchange membrane fuel cells," Journal of Power Sources, vol. 195, no. 2, pp. 466-470, 2010. 
[27] E. F. Holby, W. Sheng, Y. Shao-Horn, and D. Morgan, "Pt nanoparticle stability in PEM fuel cells: influence of particle size distribution and crossover hydrogen," Energy and Environmental Science, vol. 2, no. 8, pp. 865-871, 2009.

[28] A. M. Kannan, S. Sadananda, D. Parker, L. Munukutla, J. Wertz, and M. Thommes, "Wire rod coating process of gas diffusion layers fabrication for proton exchange membrane fuel cells," Journal of Power Sources, vol. 178, no. 1, pp. 231237, 2008.

[29] J. F. Lin, C. W. Mason, A. Adame, X. Liu, X. H. Peng, and A. M. Kannan, "Synthesis of Pt nanocatalyst with micelleencapsulated multi-walled carbon nanotubes as support for proton exchange membrane fuel cells," Electrochimica Acta, vol. 22, pp. 6496-6500, 2010. 

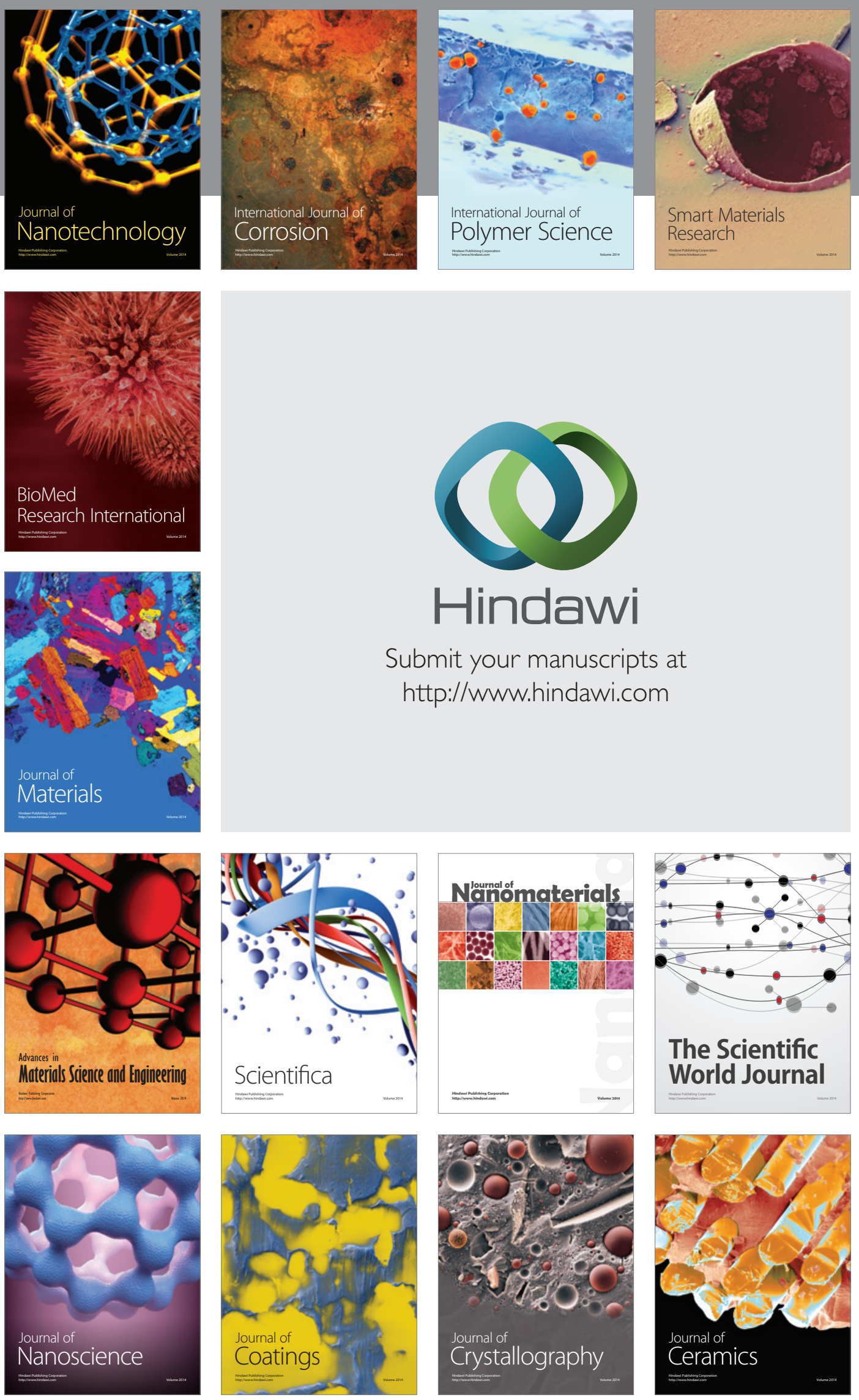

The Scientific World Journal

Submit your manuscripts at

http://www.hindawi.com

\section{World Journal}

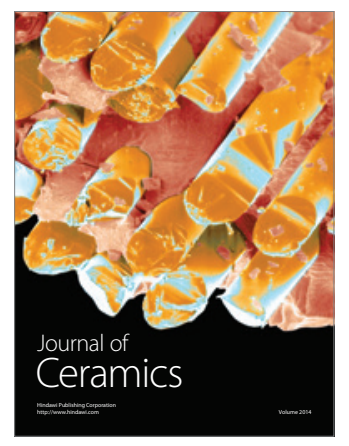

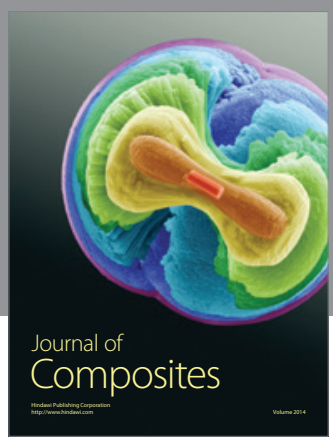
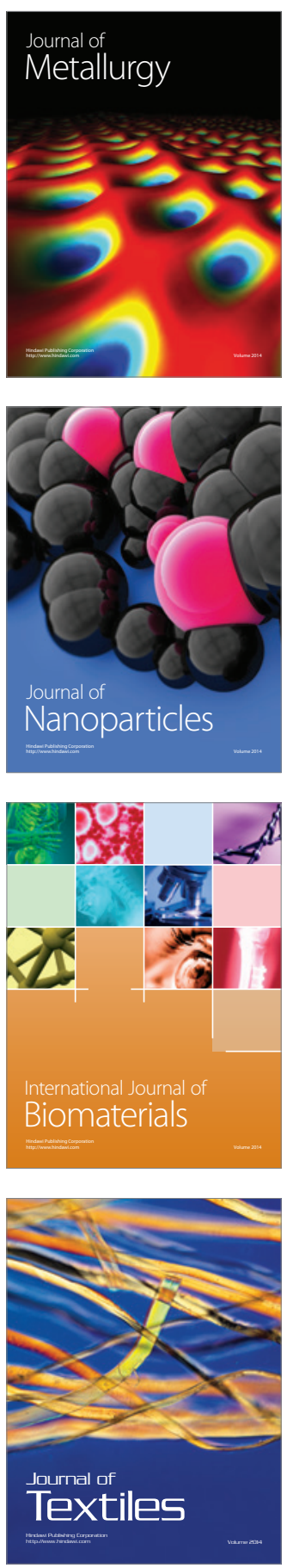